\title{
Influence of long-term exposure to loads on the annular sections' strength and rigidness
}

\author{
Victor Shchutskiy ${ }^{1, \mathrm{a}}$, Alik Blyagoz ${ }^{2, \mathrm{~b}}$, Sergey Shchutskiy ${ }^{1 *}$, Svetlana Slabukha ${ }^{1, \mathrm{~d}^{*}}$, \\ Konstantin Kurgin ${ }^{1, \mathrm{e}}$ \\ ${ }^{1}$ Don State Technical University, 344022, Rostov-on-Don, Russia \\ ${ }^{2}$ Kuban State Agrarian University named after I.T. Trubilin, 350044, Krasnodar, Russia
}

\begin{abstract}
A numerical experiment was carried out to study rigidity, critical force, and bearing capacity of reinforced concrete racks with annular section under short-term and long-term loading. The effect of longterm loading was estimated in the numerical experiment by changing the coefficient $\varphi_{l}$ from 1 to 1.8 times 0.2 , as well as the modulus of deformations $E_{b, \tau}$, taking into account the operating conditions ( $\mathrm{W}=40$ $75 \%$ ). At the same time, the external load on the rack $\mathrm{N}$ was taken in the experiments as a multiple of the critical force $\mathrm{N}_{\mathrm{cr}}$ from 0.2 to 1.0 , and the relative eccentricity $\delta_{e}$ of the load application varied from 0.15 to 1.35 , which made it possible to estimate the stress state of the struts in an extended range of possible loadings. The results obtained made it possible to identify qualitative and quantitative regularities of rigidity changes, critical force and bearing capacity of annular struts during short-term and long-term load application.
\end{abstract}

\section{Introduction}

Investigation on the centrifuged concrete properties, the strength and deformability of reinforced concrete structures of annular section, are devoted to the works of I.N. Akhverdov [1], V.M. Batashev [2,3], S.A. Dmitriev [4], A.P. Kuzis [5,6], V.N. Lebedev, T.F. Nagornaya [3] and others.

The research results of these authors were used as the basis for calculating the structures of the annular section according to the SNiP 2. 03.01-84 norms. The methodology for calculating such structures in the new standards BC 63.13330.2018 [7] has not undergone significant changes. However, we analyzed in detail some features of the calculation according to the new standards in [8].

It should be noted that most of the above-mentioned studies, including ours $[8,10]$, were based on the results of the short-term loads' impact on structures. Insufficient attention has been paid to the study of the long-term loadings influence on the operation of structures with an annular section.

\footnotetext{
*Corresponding author: svpike1@rambler.ru
} 


\section{Main part}

In this work, which is a continuation of the previous studies [8-10], the results of a numerical experiment on the study of the bearing capacity, bending rigidity and the critical force of annular struts under short-term and long-term loads are presented. A cylindrical support was adopted as a test sample PTL according to GOST 22687.2, the parameters of which are given in Table 1.

Table 1. Parameters of the investigated PTL support

\begin{tabular}{|c|c|c|c|c|c|c|}
\hline \multirow{2}{*}{$\begin{array}{c}\text { Support } \\
\text { type } \\
\text { according } \\
\text { to GOST } \\
22687.2\end{array}$} & \multicolumn{2}{|c|}{ Strut diameters, $\mathrm{mm}$} & \multirow{2}{*}{$\begin{array}{c}\text { Wall } \\
\text { thickness, } \\
\text { mm }\end{array}$} & \multicolumn{2}{|c|}{$\begin{array}{l}\text { Class and number of } \\
\text { reinforcement }\end{array}$} & \multirow{2}{*}{$\begin{array}{c}\text { Reinforcement } \\
\text { prestressing } \\
\text { level }\end{array}$} \\
\hline & External & Internal & & $\begin{array}{l}\text { Stress } \\
\text { A-IV } \\
\text { (A600) }\end{array}$ & $\begin{array}{c}\text { Non-stress } \\
\text { A-IV } \\
\text { (A600) }\end{array}$ & \\
\hline SC20.2-1.0 & 800 & 640 & 80 & $22 \mathrm{~d} 14$ & $30 \mathrm{~d} 14$ & $0.8 \mathrm{R}_{\text {sp }, \mathrm{n}}$ \\
\hline
\end{tabular}

Note. The number and diameter of the reinforcement corresponds to the most stressed strut section at the pinching level.

The assessment of the stress state of the structure under short-term and long-term loading was carried out according to the norms BC 63.13330.2018 methodology [7].

The relative height of the annular elements' compressed zone of concrete $\xi_{\text {cir: }}$ :

$$
\xi_{c i r}=\frac{N+R_{S} A_{s, t o t}}{R_{b} A_{b}+\left(R_{S c}+1,7 R_{S}\right) A_{s, t o t}}
$$

Where $A_{s, t o t}=A_{s p}+A_{s} ; A_{s p}, A_{s}$ are the areas of stress and non-stress reinforcement, respectively.

Bearing capacity of the annular section $M_{u l t}$ :

$$
M_{u l t} \leq\left(R_{b} A_{b} r_{m}+R_{s c} A_{s, t o t} r_{s}\right) \frac{\sin \left(\pi \xi_{c i r}\right)}{\pi}+R_{s} A_{s, t o t}\left(1-1.7 \xi_{c i r}\right) z_{s}
$$

Where $\mathrm{z}_{\mathrm{s}}=\left(0.2+1.3 \xi_{\text {cir }}\right) \mathrm{r}_{\mathrm{s} .}$, by that $0.15<\xi_{\text {cir }} \leq 0.6$

D-pillar flexural rigidity and critical force $\mathrm{N}_{\mathrm{crc}}$ were determined, respectively, by the formulas (3) and (4):

$$
D=D_{b}+D_{s}=\frac{0.15 E_{b} I_{b}}{\varphi_{l}\left(0.3+\delta_{e}\right)}+0.7 E_{s} I_{S}
$$

Where $D_{b}$ is concrete section rigidity, $D_{s}$ is reinforcement rigidity;

$I_{b}$ and $I_{s}$ are the moments of inertia, respectively, of the concrete section and reinforcement;

$$
\begin{aligned}
& \delta_{e}=\frac{e_{0}}{H} \text { is relative eccentricity of external load application } \mathrm{N}, \\
& H \text { defines outside diameter of the strut beam; } \\
& \varphi_{l}=1 \text { with short-term load. }
\end{aligned}
$$

$$
N_{c r}=\frac{\pi^{2} D}{l_{0}^{2}}
$$

In a numerical experiment, the value of the longitudinal force $N$ in the formula (1) varied within (0.2-1.0) $N_{c r}$, and the magnitude $\delta_{e}=0.15-1.35$. 
The effect of long-term impact of loads on bending rigidity and critical force was taken into account by changing the coefficient $\varphi_{l}$ and concrete deformation modulus $E_{b, \tau}$ by the formulas (5) and (6).

$$
\varphi_{l}=1+\beta \frac{\mathrm{M}_{l}}{\mathrm{M}}
$$

where $\beta=1$ - for heavy concrete; $M_{l}$ and $M$ are the moments from long-term and full loads, respectively.

$$
E_{b, \tau}=\frac{E_{b}}{1+\varphi_{b, c r}}
$$

where $\varphi_{b, c r}$ is a creep coefficient of concrete, depending on the strength of concrete and ambient water percentage in accordance with [7].

In a numerical experiment to expand the field of possible loadings of the strut, the change in rigidity $\mathrm{D}$ and critical force $\mathrm{N}_{\mathrm{cr}}$ was investigated for the short-term and long-term loading, depending on the relative eccentricity $\delta_{e}=0,15-1,35$ (multiples of 0.15 ). And when assessing the bearing capacity of the Mult compressive strut, depending on the relative height of the compressed zone $\xi_{\text {cir }}$ the value of $\mathrm{N}$ was taken as a multiple of $\mathrm{N}_{\text {cr }}$ from 0.2 to 1 .

Within the framework of this article, it is not possible to show the obtained research results in detail, however, the most characteristic and significant dependences are presented.

Table 2 shows the numerical values of the rigidity $D_{b}$ concrete section of the compressive strut, and Table 3 shows rigidity D of a reinforced concrete section with shortterm and long-term loading for different values $\varphi_{l}$ and operating conditions.

\begin{tabular}{|c|c|c|c|c|c|c|c|c|c|}
\hline$\delta \mathrm{e}$ & 0.15 & 0.3 & 0.45 & 0.6 & 0.75 & 0.9 & 1.05 & 1.2 & 1.35 \\
\hline \multicolumn{10}{|c|}{$\varphi_{1}=1.0$ (short-term loading) } \\
\hline$E_{b}-$ initial & 1525.29 & 1143.97 & 915.17 & 762.64 & 653.70 & 571.98 & 508.43 & 457.59 & 415.99 \\
\hline \multicolumn{10}{|c|}{$\varphi_{\mathrm{l}}=1.2$ (long-term loading) } \\
\hline $\mathrm{E}_{\mathrm{b}}-$ initial & 1271.07 & 953.31 & 762.64 & 635.54 & 544.75 & 476.65 & 423.69 & 381.32 & 346.66 \\
\hline$E_{b, \tau}(W>75 \%)$ & 552.64 & 414.48 & 331.58 & 276.32 & 236.85 & 207.24 & 184.21 & 165.79 & 150.72 \\
\hline$E_{b, \tau}(W=40-75 \%)$ & 453.95 & 340.47 & 272.37 & 226.98 & 194.55 & 170.23 & 151.32 & 136.19 & 123.81 \\
\hline $\mathrm{E}_{\mathrm{b}, \tau}(\mathrm{W}<40 \%)$ & 353.08 & 264.81 & 211.85 & 176.54 & 151.32 & 132.40 & 117.69 & 105.92 & 96.29 \\
\hline \multicolumn{10}{|c|}{$\varphi_{1}=1.4$ (long-term loading) } \\
\hline $\mathrm{E}_{\mathrm{b}}-$ initial & 1089.49 & 817.12 & 653.70 & 544.75 & 466.93 & 408.56 & 363.16 & 326.85 & 297.13 \\
\hline$E_{b, \tau}(W>75 \%)$ & 473.69 & 355.27 & 284.22 & 236.85 & 203.01 & 177.63 & 157.90 & 142.11 & 129.19 \\
\hline$E_{b, \tau}(W=40-75 \%)$ & 389.10 & 291.83 & 233.46 & 194.55 & 166.76 & 145.91 & 129.70 & 116.73 & 106.12 \\
\hline $\mathrm{E}_{\mathrm{b}, \tau}(\mathrm{W}<40 \%)$ & 302.64 & 226.98 & 181.58 & 151.32 & 129.70 & 113.49 & 100.88 & 90.79 & 82.54 \\
\hline \multicolumn{10}{|c|}{$\varphi_{\mathrm{l}}=1.6$ (long-term loading) } \\
\hline $\mathrm{E}_{\mathrm{b}}-$ initial & 953.31 & 714.98 & 571.98 & 476.65 & 408.56 & 357.49 & 317.77 & 285.99 & 259.99 \\
\hline $\mathrm{E}_{\mathrm{b}, \tau}(\mathrm{W}>75 \%)$ & 414.48 & 310.86 & 248.69 & 207.24 & 177.63 & 155.43 & 138.16 & 124.34 & 113.04 \\
\hline $\mathrm{E}_{\mathrm{b}, \tau}(\mathrm{W}=40-75 \%)$ & 340.47 & 255.35 & 204.28 & 170.23 & 145.91 & 127.67 & 113.49 & 102.14 & 92.85 \\
\hline$E_{b, \tau}(W<40 \%)$ & 264.81 & 198.61 & 158.88 & 132.40 & 113.49 & 99.30 & 88.27 & 79.44 & 72.22 \\
\hline \multicolumn{10}{|c|}{$\varphi_{\mathrm{l}}=1.8$ (long-term loading) } \\
\hline
\end{tabular}

Table 2. Concrete section of the compressive strut rigidity $D_{b}, 10^{-11} \cdot \mathrm{N} \cdot \mathrm{mm}^{2}$ 


\begin{tabular}{|c|c|c|c|c|c|c|c|c|c|}
\hline $\mathrm{E}_{\mathrm{b}}-$ initial & 847.38 & 635.54 & 508.43 & 423.69 & 363.16 & 317.77 & 282.46 & 254.21 & 231.10 \\
\hline $\mathrm{E}_{\mathrm{b}, \tau}(\mathrm{W}>75 \%)$ & 368.43 & 276.32 & 221.06 & 184.21 & 157.90 & 138.16 & 122.81 & 110.53 & 100.48 \\
\hline $\mathrm{E}_{\mathrm{b}, \tau}(\mathrm{W}=40-75 \%)$ & 302.64 & 226.98 & 181.58 & 151.32 & 129.70 & 113.49 & 100.88 & 90.79 & 82.54 \\
\hline $\mathrm{E}_{\mathrm{b}, \tau}(\mathrm{W}<40 \%)$ & 235.38 & 176.54 & 141.23 & 117.69 & 100.88 & 88.27 & 78.46 & 70.62 & 64.20 \\
\hline
\end{tabular}

Table 3. Reinforced concrete section of the compressive strut rigidity $D, 10^{-11} \cdot \mathrm{N} \cdot \mathrm{mm}^{2}$

\begin{tabular}{|c|c|c|c|c|c|c|c|c|c|}
\hline$\delta \mathrm{e}$ & 0.15 & 0.3 & 0.45 & 0.6 & 0.75 & 0.9 & 1.05 & 1.2 & 1.35 \\
\hline \multicolumn{10}{|c|}{$\varphi_{1}=1.0$ (short-term loading) } \\
\hline$E_{b}-$ initial & 2332.06 & 1950.74 & 1721.95 & 1569.42 & 1460.47 & 1378.76 & 1315.20 & 1264.36 & 1222.76 \\
\hline \multicolumn{10}{|c|}{$\varphi_{1}=1.2$ (long-term loading) } \\
\hline $\mathrm{E}_{\mathrm{b}}-$ initial & 2077.85 & 1760.08 & 1569.42 & 1442.31 & 1351.52 & 1283.43 & 1230.47 & 1188.10 & 1153.43 \\
\hline $\mathrm{E}_{\mathrm{b}, \tau}(\mathrm{W}>75 \%)$ & 1359.42 & 1221.25 & 1138.36 & 1083.09 & 1043.62 & 1014.01 & 990.99 & 972.57 & 957.49 \\
\hline $\begin{array}{c}\mathrm{E}_{\mathrm{b}, \tau}(\mathrm{W}=40- \\
75 \%)\end{array}$ & 1260.73 & 1147.24 & 1079.15 & 1033.75 & 1001.33 & 977.01 & 958.09 & 942.96 & 930.58 \\
\hline $\begin{array}{c}\mathrm{E}_{\mathrm{b}, \tau}(\mathrm{W}< \\
40 \%) \\
\end{array}$ & 1159.85 & 1071.58 & 1018.62 & 983.31 & 958.09 & 939.18 & 924.47 & 912.70 & 903.07 \\
\hline \multicolumn{10}{|c|}{$\varphi_{1}=1.4$ (long-term loading) } \\
\hline $\mathrm{E}_{\mathrm{b}}$ - initial & 1896.27 & 1623.89 & 1460.47 & 1351.52 & 1273.70 & 1215.33 & 1169.94 & 1133.62 & 1103.91 \\
\hline $\mathrm{E}_{\mathrm{b}, \tau}(\mathrm{W}>75 \%)$ & 1280.47 & 1162.04 & 1090.99 & 1043.62 & 1009.79 & 984.41 & 964.67 & 948.88 & 935.96 \\
\hline $\begin{array}{c}\mathrm{E}_{\mathrm{b}, \tau}(\mathrm{W}=40- \\
75 \%)\end{array}$ & 1195.88 & 1098.60 & 1040.24 & 1001.33 & 973.53 & 952.69 & 936.48 & 923.51 & 912.89 \\
\hline $\begin{array}{c}\mathrm{E}_{\mathrm{b}, \tau}(\mathrm{W}< \\
40 \%)\end{array}$ & 1109.41 & 1033.75 & 988.36 & 958.09 & 936.48 & 920.26 & 907.65 & 897.57 & 889.31 \\
\hline \multicolumn{10}{|c|}{$\varphi_{1}=1.6$ (long-term loading) } \\
\hline $\mathrm{E}_{\mathrm{b}}-$ initial & 1760.08 & 1521.75 & 1378.76 & 1283.43 & 1215.33 & 1164.26 & 1124.54 & 1092.77 & 1066.77 \\
\hline $\mathrm{E}_{\mathrm{b}, \tau}(\mathrm{W}>75 \%)$ & 1221.25 & 1117.63 & 1055.46 & 1014.01 & 984.41 & 962.20 & 944.93 & 931.12 & 919.81 \\
\hline $\begin{array}{c}\mathrm{E}_{\mathrm{b}, \tau}(\mathrm{W}=40- \\
75 \%)\end{array}$ & 1147.24 & 1062.12 & 1011.05 & 977.01 & 952.69 & 934.45 & 920.26 & 908.91 & 899.63 \\
\hline $\begin{array}{c}\mathrm{E}_{\mathrm{b}, \tau}(\mathrm{W}< \\
40 \%)\end{array}$ & 1071.58 & 1005.38 & 965.66 & 939.18 & 920.26 & 906.08 & 895.04 & 886.22 & 878.99 \\
\hline \multicolumn{10}{|c|}{$\varphi_{1}=1.8$ (long-term loading) } \\
\hline$E_{b}-$ initial & 1654.16 & 1442.31 & 1315.20 & 1230.47 & 1169.94 & 1124.54 & 1089.24 & 1060.99 & 1037.88 \\
\hline $\mathrm{E}_{\mathrm{b}, \tau}(\mathrm{W}>75 \%)$ & 1175.20 & 1083.09 & 1027.83 & 990.99 & 964.67 & 944.93 & 929.58 & 917.30 & 907.25 \\
\hline $\begin{array}{c}\mathrm{E}_{\mathrm{b}, \tau}(\mathrm{W}=40- \\
75 \%)\end{array}$ & 1109.41 & 1033.75 & 988.36 & 958.09 & 936.48 & 920.26 & 907.65 & 897.57 & 889.31 \\
\hline $\begin{array}{c}\mathrm{E}_{\mathrm{b}, \tau}(\mathrm{W}< \\
40 \%) \\
\end{array}$ & 1042.16 & 983.31 & 948.00 & 924.47 & 907.65 & 895.04 & 885.24 & 877.39 & 870.97 \\
\hline
\end{tabular}

It should be noted that the concrete section rigidity of the compressive strut $D_{b}$ according to formula (3) varies proportionally $E_{b}$ and inversely proportional to the load duration factor $\varphi_{l}$. Therefore, in Tables 2, 3 and in the graphs in Fig. 1 the values $D_{b}$ are given under various $\varphi_{l}$ for the initial modulus of elasticity $E_{b}$ (short-term load) and $E_{b, \tau}$ (continuous load) at three values of operating conditions.

Analysis of these graphs (refer with Fig. 1) shows that the rigidity of the compressive strut $D_{b}$ (all other things being equal), the main influence is exerted by the relative eccentricity of the load application $\delta_{e}$. In this case, the functional dependence $D_{b}=f\left(\delta_{e}\right)$ and $D=f\left(\delta_{e}\right)$ is nonlinear, which is obvious from the formula (3).

Operating conditions $W$-ambient water percentage and associated values $E_{b, \tau}$ have less impact on rigidity $D_{b}$ and $D$, and the form of the function $D_{b}=f\left(\delta_{e}\right)$ and $D=f\left(\delta_{e}\right)$ remains unchanged, and the graphs converge with magnification $\delta_{e}$.

So, for example, the rigidity $D_{b}$ ( by $\varphi_{l}=1.2$ and $\mathrm{W}=$ more $75 \%$ ) changed from $552.64 \cdot 10^{8} \mathrm{kNmm}^{2}$ (by $\delta_{e}=0.15$ ) to $150.72 \cdot 10^{8} \mathrm{kNmm}^{2}$ (by $\delta_{e}=1.35$ ), that is, it decreased by 3.66 times. Moreover, for any value $\delta_{e}$ moisture change $\mathrm{W}=40 \div 75 \%$, leads to 
a decrease in rigidity $D_{b}$ in 1.565 times. This pattern is true for every row and every column of values $D_{b}$ (refer with Table 2).

Influence on eccentricity $\delta_{e}$ full rigidity $D$ (refer with Table 3 ) affects several times less than $D_{b}$, which is explained by the weight fraction of reinforcement rigidity $D_{s}$ in the total rigidity of the compressive strut section.

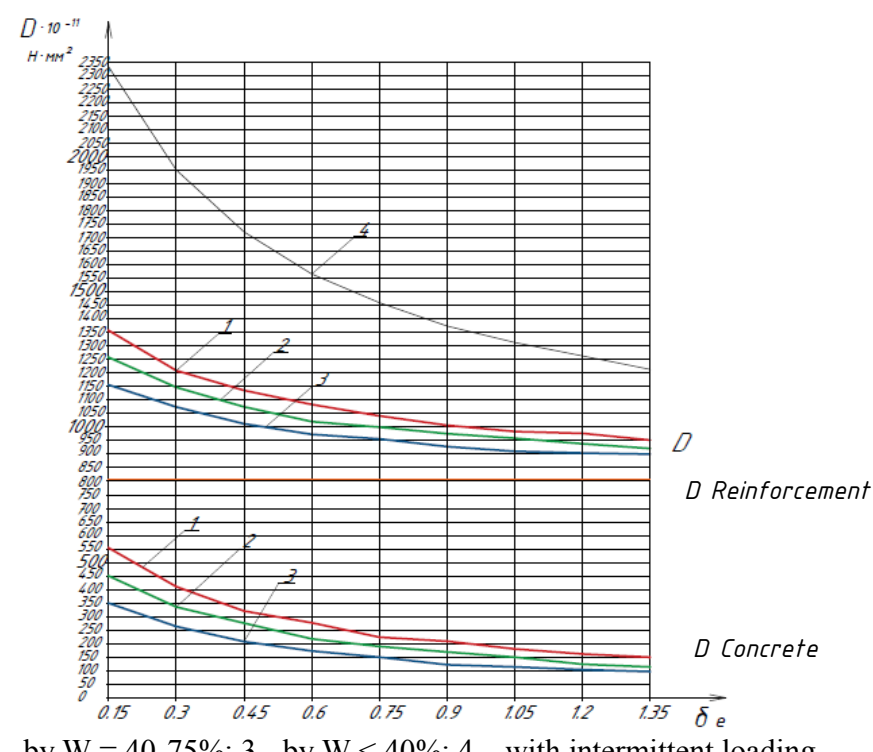

1 - by $\mathrm{W}>75 \% ; 2$ - by $\mathrm{W}=40-75 \% ; 3$ - by $\mathrm{W}<40 \% ; 4$ - with intermittent loading.

Fig. 1. Change in rigidity $D_{b}-$ concrete section and $D-$ reinforced concrete section from relative eccentricity (at $\varphi_{l}=1.2$ );

So, for example, the rigidity $D$ (by $\varphi_{l}=1.2$ and $\mathrm{W}=$ more $75 \%$ ) is changed from $1359.42 \cdot 10^{8} \mathrm{kNmm}^{2}$ (by $\delta_{e}=0.15$ ) to $957.49 \cdot 10^{8} \mathrm{kNmm}^{2}$ (by $\delta_{e}=1.35$ ), that is, decreased in 1,42 times.

At the same time, the change in the water percentage of the environment $\mathrm{W}$ with prolonged exposure to load on full rigidity $D$ much less than $D_{b}$.

For example, changing $\mathrm{W}=40-75 \%\left(\varphi_{l}=1.2, \delta_{e}=0.15\right)$ leads to a decrease in rigidity with $1359.42 \cdot 10^{8} \mathrm{kNmm}^{2}$ to $1159.85 \cdot 10^{8} \mathrm{kNmm}^{2}$, i.e. by $17 \%$. Moreover, in each row and each column of Table 3, this change will be different, which is associated with the influence of the rigidity of the reinforcement $D_{s}$ on the total rigidity of the compressive strut $\mathrm{D}$ section.

Table 4 shows the numerical values of the critical force of the compressive strut $N_{c r}$ depending on the relative eccentricity $\delta_{e}$ and the coefficient $\varphi_{l}$, taking into account the duration of the load, and in fig. 2 - graphs of changes $N_{c r}=f\left(\delta_{e}\right)$.

It should be noted that the nature of the change in function $N_{c r}=f\left(\delta_{e}\right)$ is similar to the function $D=f\left(\delta_{e}\right)$, which is obvious from the formula (4).

Table 4. Critical force change $\mathrm{N}_{\mathrm{cr}} \cdot 10^{-8}, \mathrm{kN}$ depending on relative eccentricity and water percentage W.

\begin{tabular}{|c|c|c|c|c|c|}
\hline$\phi_{1} / \delta \mathrm{e}$ & $\varphi_{1}=1$ & $\varphi_{1}=1.2$ & $\varphi_{1}=1.4$ & $\varphi_{1}=1.6$ & $\varphi_{1}=1.8$ \\
\hline & & \multicolumn{5}{|c|}{$\mathrm{W}>75 \%$} \\
\hline 0.15 & 2554.80 & 1489.25 & 1402.77 & 1337.90 & 1287.45 \\
\hline 0.45 & 1886.41 & 1247.08 & 1195.19 & 1156.27 & 1126.00 \\
\hline 0.75 & 1599.96 & 1143.30 & 1106.23 & 1078.43 & 1056.81 \\
\hline
\end{tabular}




\begin{tabular}{|l|c|c|c|c|c|}
\hline 1.05 & 1440.82 & 1085.64 & 1056.81 & 1035.19 & 1018.37 \\
\hline 1.35 & 1339.55 & 1048.95 & 1025.36 & 1007.67 & 993.91 \\
\hline & & \multicolumn{5}{|c|}{$\mathrm{W}=40 \div 75 \%$} \\
\hline 0.15 & 2554.80 & 1381.14 & 1310.10 & 1256.81 & 1215.37 \\
\hline 0.45 & 1886.41 & 1182.22 & 1139.59 & 1107.62 & 1082.76 \\
\hline 0.75 & 1599.96 & 1096.96 & 1066.52 & 1043.68 & 1025.92 \\
\hline 1.05 & 1440.82 & 1049.60 & 1025.92 & 1008.16 & 994.34 \\
\hline 1.35 & 1339.55 & 1019.46 & 1000.09 & 985.55 & 974.25 \\
\hline & & \multicolumn{5}{|c|}{$\mathrm{W}<40 \%$} \\
\hline 0.15 & 2554.80 & 1270.63 & 1215.37 & 1173.93 & 1141.70 \\
\hline 0.45 & 1886.41 & 1115.91 & 1082.76 & 1057.89 & 1038.55 \\
\hline 0.75 & 1599.96 & 1049.60 & 1025.92 & 1008.16 & 994.34 \\
\hline 1.05 & 1440.82 & 1012.76 & 994.34 & 980.53 & 969.79 \\
\hline 1.35 & 1339.55 & 989.32 & 974.25 & 962.95 & 954.16 \\
\hline
\end{tabular}
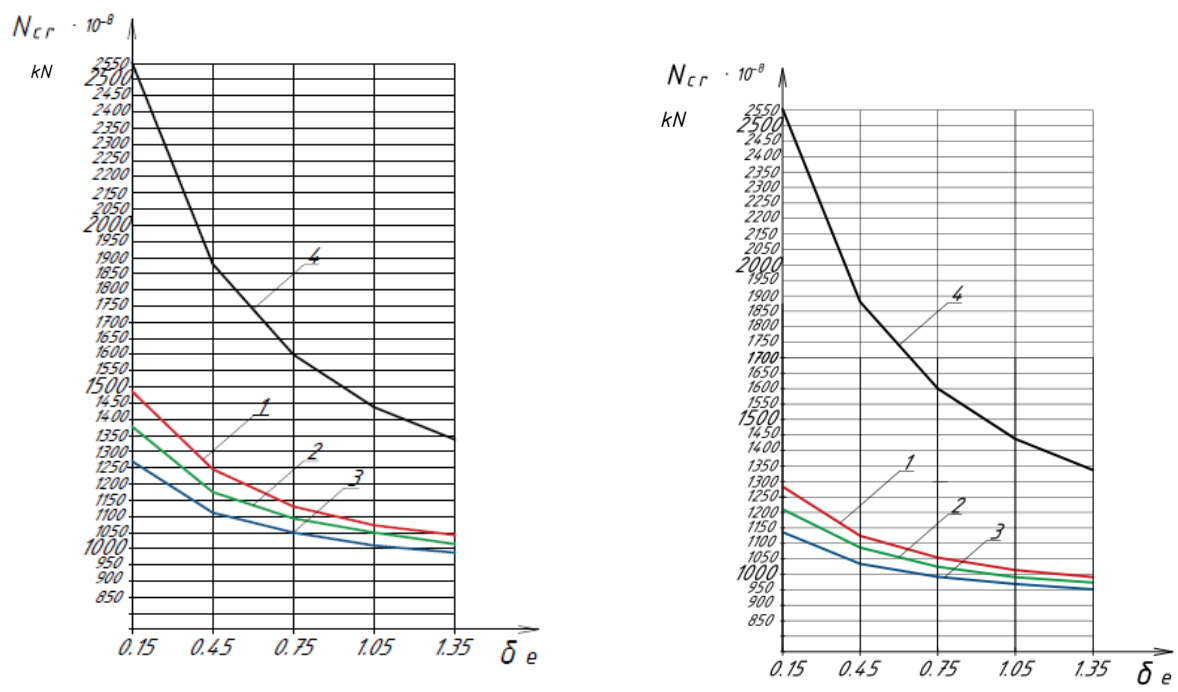

1 - by W $>75 \% ; 2$ - by W $=40-75 \% ; 3$ - by $\mathrm{W}<40 \% ; 4$ - with intermittent loading.

Fig. 2. Change in critical force $N_{c r}$ from relative eccentricity a) by $\varphi_{l}=1.2$; b) by $\varphi_{l}=1.8$

These graphs analysis shows that the main influence on the critical strength of the compressive strut $N_{c r}$ has a relative eccentricity of the load application $\delta_{e}$. In this case, the influence of the load duration factor $\varphi_{l}$ on the critical force of the compressive strut $N_{c r}$ disproportionate to the change in value $\varphi_{l}$. This is due to the lack of a clear influence of the coefficient $\varphi_{l}$ for rigidity $D_{s}$.

Incomplete studies of the bearing capacity of the compressive struts $M_{u l t}$ showed that the main influence on the bearing capacity is exerted by the value of the relative compressed zone of concrete $\xi_{c i r}$ and the relationship $N / N_{c r c}$. Wherein $M_{u l t}$ is increased with increasing $N / N_{c r c}$, reaching the maximum value at a certain value $N / N_{c r c}$ (refer with Fig.3). 


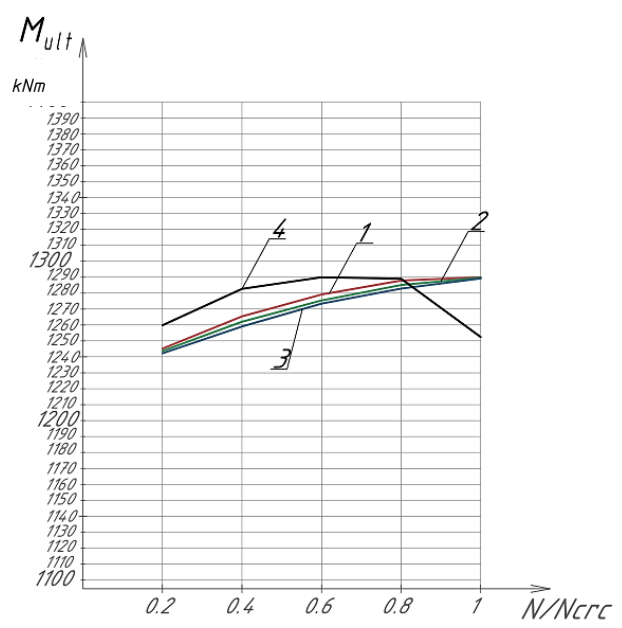

1 - by $\mathrm{W}>75 \% ; 2$ - by $\mathrm{W}=40-75 \% ; 3$ - by $\mathrm{W}<40 \% ; 4$ - with intermittent loading.

Fig. 3. Change in bearing capacity $M_{u l t}$ depending on the $N / N_{c r c}$ proportion

\section{Conclusion}

1. Rigidity $D$ of the annular struts with increasing eccentricity of load application $\delta_{e}$ decreases with both short-term and long-term exposure to loads. In this case, the functional dependence $D=f\left(\delta_{e}\right)$ is non-linear.

2. Prolonged exposure to loads leads to a decrease in the rigidity of the concrete section $D_{b}$ proportional to the increase in the coefficient $\varphi_{l}$ and inversely proportional to the change in the deformation modulus $\mathrm{E}_{\mathrm{b}, \tau}$. (refer with Fig. 1). For any combination $\varphi_{l}$ and $\delta_{e}$ change in environmental water percentage $\mathrm{W}$ from $75 \%$ till $40 \%$ leads to a decrease in rigidity $D_{b}$ for 1,565 times. A change in the relative eccentricity of the load application from 0.15 to 1.35 leads to a decrease in rigidity $D_{b}$ in 3,66 times for any values $\varphi_{l}$ and $\mathrm{W}$.

3. The parameters $\varphi_{l}$ and $\mathrm{E}_{\mathrm{b}}, \tau$ influence to the full rigidity of the compressive strut section $\mathrm{D}$ affects less than the concrete section $D_{b}$ rigidity (refer with Table 3 ). W change from $75 \%$ till $40 \%$ for each $\varphi_{l}$ from 1,2 till 1,8 leads to a decrease in total rigidity D by $\delta_{e}=$ 0,15 from $17 \%$ to $13 \%$, and at $\delta_{e}=1,35$ from $6 \%$ to $4,1 \%$. This is a decrease in the influence of parameters $\varphi_{l}$ and $\mathrm{W}$ the total rigidity is related to the weight fraction of the reinforcement rigidity $D_{s}$ in the overall rigidity of the compressive strut D.

4. Critical force of the annular strut $N_{c r}$ (ceteris paribus) is decreased with increasing eccentricity of load application $\delta_{e}$ both for short-term and long-term loading. Functional dependence $N_{c r c}=f\left(\delta_{e}\right)$ is nonlinear (refer with Fig. 2). With $\varphi_{l}$ increase there is a decrease in critical force $N_{c r}$ out of proportion to the value $\varphi_{l}$.

5. Preliminary study of the bearing capacity of the compressive strut $M_{u l t}$ (according to formula 2) revealed that $M_{u l t}$ is increased with increasing ratio $N / N_{c r}$, reaching a maximum within the acceptable values $N / N_{c r}=0.1 \div 1$ (refer with Fig.3).

The authors plan to continue researching the bearing capacity of the compressive struts $M_{u l t}$ depending on different combinations $\varphi_{l}, \delta_{e}, \mathrm{E}_{\mathrm{b}}, \tau, N / N_{c r c}$ for the purpose of building dependency monograms $M_{u l t}$ from $N / N_{c r c}$ and percentage of compressive strut reinforcement. 


\section{References}

1. N.N. Akhverdov, Reinforced concrete centrifuged pressure pipes (Gosstroyizdat, 1969).

2. V.M. Batashev, Strength, compressive strut resistance and deformation of reinforced concrete elements with multi-row reinforcement (Kiev, Budivelnik, 1978).

3. V.M. Batashchev, S.T. Androsov, V.N. Lebedyev, T.F. Nagornaya, Concrete and reinforced concrete 5, 31-34.

4. S.A. Dmitriyev, V.M. Batashchev, Deformations (deflections) of reinforced concrete elements of annular section and opening of ccompressive struts in them, Proceedings of SRI RC "Features of concrete and reinforced concrete deformations and the use of computers to assess their impact on the behavior of structures" (Stroyizdat, Moscow, 1969).

5. A.P. Kudzyiv, On the strength calculation of eccentrically compressed elements of an annular section at low eccentricities, Proceedings "Research on reinforced concrete structures", Vilnius, 1969.

6. A.P. Kudzyiv, Reinforced concrete structures of annular section (Vilnius, Mintis, 1975).

7. BC 63.13330.2012 Concrete and reinforced concrete structures. Basic Provisions, SNiP 52-01-2003, Moscow, 2012.

8. V.L. Shchutskiy, A.S. Nasevich, V.E. Chubarov, A.M. Blyagoz, The research on bearing capacity of supports with annular section (Investigation of the bearing capacity of the annular cross-section compressive struts) CATPID-2019 IOP Conf. Series: Materials Science and Engineering 698022089 (2019). doi:10.1088/1757899X/698/2/022089

9. A.S. Nasevich, V.L. Shchutskiy, S.A. Stelmakh, O.V. Antipov, Compressive strut strength and deformability of power transmission line conical poles

10. D.A. Dedukh, V.L. Schuzkiy, A.A. Kuzmenko, Magazine of Civil Engineering 7 (2017). 